\title{
Número de chamada: estudo das práticas adotadas nas bibliotecas universitárias federais brasileiras
}

\author{
Rita de Cassia do Vale Caribé \\ Universidade de Brasília, Faculdade de Ciência da Informação, Brasília, DF, Brasil \\ rita.caribe@gmail.com \\ Ana Izabel da Silva Souza Rocha \\ Instituto de Previdência Complementar do Correios (Postalis). Brasília, DF, Brasil \\ ana.is.izabel@hotmail.com
}

DOI: https://doi.org/10.26512/rici.v13.n3.29758

Recebido/Recibido/Received: $2020-02-27$

Aceitado/Aceptado/Accepted: 2020-07-14

Resumo: A pesquisa teve como objetivo analisar as práticas adotadas nas bibliotecas universitárias brasileiras, identificando os elementos utilizados na construção do número de chamada, buscando semelhanças nas suas escolhas e na forma de os utilizar, bem como a aderência com a literatura da área. Trata-se de uma pesquisa de abordagem qualitativa descritiva combinada com quantitativa, com uso de questionário para coleta de dados, via e-mail, por meio do Google forms. A amostra não probabilística acidental foi utilizada, ou seja, foram consideradas as bibliotecas que responderam ao questionário, 26 respondentes, o que corresponde a 38,24\% do total de 68 universidades federais brasileiras. As respostas obtidas evidenciaram que a composição do número de chamada é diversificada, sendo observada reduzida convergência em termos de similitudes nas práticas adotadas, bem como alguma compatibilidade com a literatura especializada na área, o que indica a necessidade de novos estudos.

Palavras-chave: Biblioteca universitária. Número de chamada. Brasil.

\section{Call number: study of practices adopted in Brazilian federal academic libraries}

Abstract: The research aimed to analyse the practices used in Brazilian academic libraries, identifying the elements used in the construction of the call number, looking for similarities in their choices and ways of using them, as well as adherence with the literature in the area. This is a qualitative descriptive research combined with quantitative, using a questionnaire to collect data, via email, through Google forms. The accidental nonprobabilistic sample was used, that is, the 26 libraries that answered the questionnaire were considered, which corresponds to $38,24 \%$ of the total of 68 Brazilian federal universities. The responses obtained showed that the composition of the call number is diverse, with reduced convergence in terms of similarities in the practices adopted, as well as some compatibility with the specialized literature in the area, which indicates the need for further studies.

Keywords: Academic library. Call number. Brazil.

Número de llamada: estudio de prácticas adoptadas en bibliotecas universitarias federales brasileñas

Resumen: La investigación tuvo como objetivo analizar las prácticas adoptadas en las bibliotecas universitarias brasileñas, identificando los elementos utilizados en la construcción del número de llamada, buscando similitudes en sus elecciones y en la forma de usarlas, así como su adhesión a la literatura. Esta es una investigación descriptiva cualitativa combinada con investigación cuantitativa, que utiliza un cuestionario para recopilar datos, por correo electrónico, a través de formularios de Google. Se utilizó una muestra no probabilística accidental, es decir, 26 encuestados fueron consideradas las bibliotecas que respondieron el cuestionario, que corresponde al 38,24\% del total de 68 universidades federales brasileñas. Las respuestas obtenidas mostraron que la composición del número de llamada es diversa, con una convergencia reducida en 
términos de similitudes en las prácticas adoptadas, así como cierta compatibilidad con la literatura especializada en el tema, lo que indica la necesidad de más estudios.

Palavras clave: Número de llamada. Biblioteca universitaria. Brasil.

\section{Introdução}

Os recursos informacionais de uma biblioteca podem ser organizados de conformidade com

[...] uma característica externa (tamanho, tipo de encadernação, tipo de suporte) ou interna (pelo assunto que contém). Independentemente do tipo de organização adotada é necessário identificar cada recurso e agregar-lhe elementos, símbolos ou notações que possibilitem a sua identificação e localização dentro da coleção (CARIBÉ, 2019, p. 129).

São esses elementos, símbolos ou notações, que irão compor o número de chamada, expressão criada nos Estados Unidos, quando os usuários não tinham acesso às estantes. Os usuários pesquisavam no catálogo da biblioteca, extraiam o número ou conjunto de símbolos que correspondiam ao documento que desejavam e o entregavam ao bibliotecário para que o trouxesse do acervo fechado. Por meio desse número o documento era requisitado ou "chamado" do acervo, e então entregue ao usuário. Assim, surgiu o termo call number ou número de chamada (COMAROMI, 1981; PINHEIRO, 2007, RANGANATHAN, 1967; TAYLOR; JOUDREY, 2009).

O número de chamada reveste-se de importância pois encontra-se entre os metadados que descrevem os recursos informacionais. Ele se constitui em um dado de localização do documento, viabilizando acesso ao item catalogado; tem como finalidade identificar cada obra e determinar sua exata posição dentro da coleção, possibilitando sua ordenação e recuperação (TAYLOR, 2006; TAYLOR; JOUDREY, 2009). Além dos autores citados, Mey (1987, p. 91-92) argumenta que o número de chamada, além de localizador, é considerado ponto de acesso, na medida em que "permite o acesso à localização ou representação de um item específico".

O estudo dos números de chamada, de maneira geral, independentemente de relacionar-se à localização fixa ou relativa, teve seu apogeu nos séculos XIX e XX, quando as discussões sobre o tema tiveram início e foram publicados diversos artigos nos periódicos: Library Journal, The Library World e Public Libraries, conforme histórico apresentado por Caribé (2016).

Na literatura, Comaromi (1981), Ranganathan (1967) e Satija (1990) definem que o número de chamada é composto pela marca de coleção; número de classificação ou notação de classificação e número do livro (book number) que se subdivide em: marca de autor, marca da obra, marca de edição, marca de volume e marca de exemplar. No entanto, Lentino (1967) acredita que há casos em que é necessário adicionar outros elementos para individualizar essas obras, ou seja, construir notações mais 
complexas, pois em grandes bibliotecas e bibliotecas especializadas pode haver 20, 30, 50 ou mais obras sobre um mesmo assunto, traduções, e diversos tipos de obras relacionadas a outras no acervo.

$\mathrm{Na}$ literatura brasileira, os documentos detectados sobre o assunto são em quantidade reduzida e a pesquisa é praticamente inexistente, conforme relatou Caribé (2019) em seu estudo. Diante dessa realidade, esta pesquisa tem como objetivo analisar as práticas adotadas pelas bibliotecas brasileiras para construção do número de chamada. Para isso, foram identificados os elementos utilizados e a forma como as características do documento são representadas no número de chamada (exemplificando: se a obra é uma tradução, como esta característica é representada). Foram analisadas as similitudes e diferenças nas escolhas dos elementos e nas práticas adotadas, bem como a aderência com a literatura.

Além dos elementos convencionais já citados, há documentos cujas características podem ser consideradas como casos especiais: diferentes títulos de mesmo autor; diversas obras com títulos semelhantes; diversificadas traduções e para idiomas diferentes; obras clássicas e suas respectivas traduções, comentários e obras de referência relacionadas; obras relacionadas; edições variadas; editoras variadas; biografias e autobiografias; suplementos; dentre outras características que precisam ser consideradas para fins de organização nas estantes (COMAROMI, 1981; LEHNUS, 1978; RANGANATHAN, 1967). Cabe destacar que cada elemento tem uma função específica, e diversos autores citados nesta pesquisa apresentam formas semelhantes de os registrar.

$\mathrm{Na}$ literatura foi identificado estudo relativo ao número de chamada nas bibliotecas da Universidade Nacional do Prata (UNLP), realizado na Argentina, por Kessler (2011). A autora partiu das hipóteses de que há um padrão na construção dos números de classificação a partir da Classificação Decimal Universal (CDU), sistema adotado pelas bibliotecas, e uma dispersão nos elementos que compõem o book number ou signatura librística. Os resultados evidenciaram que não há padronização quanto ao uso da CDU, uso de notações mais genéricas ou específicas, bem como quanto ao uso de suas tabelas auxiliares. Com relação aos demais elementos que integram o número de chamada não foram observadas convergências nas práticas. Dentro da signatura librística a autora inclui: número de exemplar, número de edição ou reimpressão, número de inventario, número de registro e a disponibilidade (empréstimo ou sala de leitura), e idioma do documento. Esses elementos não encontram total aderência com a literatura consultada neste estudo. Outra diferença encontrada refere-se à disponibilidade, essa informação está subentendida na marca de coleção.

Quanto à metodologia, esta consiste em uma pesquisa exploratória, de abordagem qualitativa descritiva - que tem a função de descrever as características de um fenômeno, pois ainda não se tem suficiente clareza quanto às práticas adotadas nas bibliotecas brasileiras -, combinada com a 
abordagem quantitativa, pois parte dos dados foram tratados de forma estatística. 0 método indutivo também foi utilizado, na medida em que partiu de bibliotecas específicas na tentativa de identificar as práticas comuns, buscando similitudes e diferenças. (GIL, 2008; RICHARDSON, 1999).

Considerando a impossibilidade técnica e financeira de realizar um levantamento junto a todas as bibliotecas brasileiras, optou-se por selecionar um conjunto que atendesse aos requisitos da pesquisa: possuir grandes e diversificados acervos em termos de assunto, suporte e obras relacionadas. Observou-se que as bibliotecas universitárias se constituem em um laboratório propício para o desenvolvimento desta pesquisa, pois integram o grupo acima, cujas obras possuem características que precisam ser consideradas para fins de sua individualização, requerendo um alto nível de especificidade na construção do número de chamada.

No Brasil, existem 68 universidades federais, entretanto, nem todas responderam ao questionário. Neste caso, foi utilizada a amostra não probabilística acidental (RICHARDSON, 1999), ou seja, as bibliotecas das universidades federais que responderam ao questionário, no caso 26 respondentes, o que corresponde a 38,24\% do total. Foi realizado pré-teste em três bibliotecas, entre os dias 17 e 19 de maio de 2017, que resultou na reformulação de questões do questionário.

O questionário, desenvolvido a partir da revisão de literatura, possui 25 questões, sendo 10 fechadas e 15 abertas, divididas em: identificação da biblioteca (questão 1); caracterização do número de chamada (questões 2 a 14) e, como se dá o tratamento de obras relacionadas (questões 15 a 25 ). Deve-se registrar que um mesmo assunto foi perguntado de formas diferentes (aberta ou fechada) com o objetivo de evitar desvios ou inconsistências na análise de dados. O questionário foi encaminhado via e-mail, no período entre dia 25 de maio e 13 de junho de 2017 (20 dias), por meio de um link para acesso a partir da ferramenta Google Forms, por meio da qual foram recebidas todas as respostas. No apêndice encontra-se cópia do questionário utilizado.

Neste artigo, devido às características restritivas inerentes ao tipo de fonte (artigo de periódico) delimitarem a quantidade de páginas, optou-se por não incluir a revisão da literatura nos moldes tradicionais, mas incorporá-la na análise dos dados, recorrendo à literatura para explicar, justificar, referendar ou refutar a realidade observada.

\section{Apresentação e análise dos dados}

A primeira questão teve como objetivo identificar as bibliotecas universitárias que participaram da pesquisa. Foram identificadas bibliotecas centrais e setoriais que realizam o processamento técnico de maneira não centralizada. 
A pergunta dois, de tipo objetiva (sim e não) questionou quanto a utilização do número de chamada, entendido, conforme já explicitado, como aquele conjunto de elementos que permite localizar o documento dentro do acervo, independentemente do tipo de sistema utilizado - localização fixa ou relativa. As respostas a esta questão evidenciaram que $96 \%$ dos respondentes utilizam o número de chamada como forma de localizar os documentos em seus acervos.

As respostas à questão três (pergunta fechada, sim e não) evidenciaram que $96 \%$ dos respondentes utilizam um sistema para codificação do autor. Apenas $4 \%$ (um respondente) não utiliza nenhum sistema para codificar autor.

Observou-se que a instituição que respondeu não utilizar o número de chamada adota a localização fixa. Neste caso pode-se inferir que há um problema de entendimento conceitual por parte daquele que respondeu ao questionário. O número de chamada independe do sistema adotado. Mesmo com a localização fixa são utilizados elementos para localizar os documentos nas estantes e estes se constituem em número de chamada, podendo ser construído com o número da sala, estante, prateleira e a posição na prateleira (PINHEIRO, 2007).

Quanto ao sistema utilizado para codificar o autor (questão 4), os respondentes poderiam escolher entre as alternativas Cutter, Cutter-Sanborn, Tabela PHA, Numeração fixa ou outro. Das 25 bibliotecas que utilizam um sistema para codificar autor, $48 \%$ responderam que utilizam o sistema Cutter-Sanborn; $28 \%$ o sistema Cutter e $16 \%$ não identificaram o sistema utilizado. Duas bibliotecas (8\%) utilizam as três primeiras letras do sobrenome do autor acompanhado das iniciais do título separados por uma barra ( / ) e nenhuma biblioteca utiliza a tabela PHA.

Quanto às respostas à questão quatro cabem algumas reflexões. Foram incluídos os dois tipos de tabelas de Cutter (Cutter e Cutter-Sanborn). Observou-se que $48 \%$ responderam que utilizam o sistema de Cutter, o que foi uma surpresa, pois se acreditava que no Brasil fosse mais utilizada a tabela de Cutter-Sanborn, por ter sido traduzida para o português e ser mais citada nos livros de classificação e catalogação editados no Brasil. Por outro lado, a questão pode ter tido seu entendimento prejudicado, pois muitas vezes os bibliotecários adotam apenas o termo Cutter para se referir à tabela de Cutter-Sanborn. Fato semelhante ocorre nos Estados Unidos, Taylor e Joudrey (2009) afirmam que se usa o termo cutter, em minúscula, para se referir à notação de autor. É o caso da marca que se tornou sinônimo do produto. De qualquer forma, constata-se que as tabelas de Cutter (Cutter - 28\% e Cutter-Sanborn - 48\%) são utilizadas por 76\% das bibliotecas universitárias pesquisadas.

Cabe registrar, também, que no questionário não foi explicitado o significado dos termos: tabela de Cutter - corresponde à tabela de dois dígitos elaborada por Cutter; tabela de Cutter-Sanborn - corresponde à tabela de três dígitos elaborada por Cutter e Kate Sanborn. Acreditava-se que esse 
conhecimento fosse de domínio dos bibliotecários respondentes, por estar incluído dentre as áreas tronco da Biblioteconomia. Este fato pode ter sido um fator que contribuiu para as respostas apresentadas.

Outra resposta que merece reflexão refere-se ao uso, por $8 \%$ (duas) das bibliotecas pesquisadas, das três primeiras letras do sobrenome do autor ou menção nominal, acompanhados das iniciais do título separados por barra. Cabe ressaltar que o uso da barra para separar autor do título não foi identificada na literatura. Jast (1901a, 1901b) orienta o uso do ponto para separar a notação de autor da marca da obra.

Há controvérsias quanto ao uso da menção nominal na literatura. Autores como Cutter e Dewey (apud OSBORN, 1982) e Ranganathan (1967) consideram o uso das três primeiras letras do sobrenome do autor ou menção nominal como um método reacionário e rígido, que não diferencia exemplares, edições, volumes nem autores que possuem sobrenomes semelhantes. Corroborando essas afirmativas, Slavic (2006) aponta diversos problemas decorrentes do uso das três primeiras letras do sobrenome do autor utilizado em biblioteca da Croácia, especialmente quanto a autores cujos sobrenomes começam com as mesmas letras. Mey (1995) por outro lado, argumenta que a menção nominal é utilizada por diversas bibliotecas da Europa e pode ser adotada em qualquer tipo de biblioteca, até mesmo aquelas com grandes acervos.

Retomando a análise das respostas, a questão cinco (questão fechada, sim e não) perguntou se a biblioteca utilizava algum elemento no número de chamada para evidenciar que o documento é um tipo de caso especial. O que são considerados casos especiais foi explicitado acima. Embora os acervos sejam grandes, dois respondentes (8\%) indicaram que não utilizam nenhum critério para casos especiais no número de chamada.

A questão seis, questão aberta, perguntou quais eram os elementos utilizados para compor o número de chamada, cujas respostas foram sintetizadas no quadro 1. Cabe ressaltar que, as células do quadro 1, que se encontram em branco, significa que o respondente não indicou este elemento como integrante do número de chamada utilizado na biblioteca.

Observou-se que $92 \%$ utilizam um sistema de classificação para organizar os recursos informacionais físicos, agrupando os semelhantes, constatação esta que vai ao encontro de diversos autores citados. Significa, também, que $92 \%$ dos respondentes consideram a notação de classificação como integrante do número de chamada.

Embora não seja objetivo desta pesquisa identificar os sistemas de classificação mais utilizados, ficou evidenciado que a CDD é utilizada por 12 (48\%) bibliotecas, enquanto a CDU é utilizada apenas por 2 (8\%) bibliotecas. Uma biblioteca declarou utilizar a CDD combinada com a Classificação 
Decimal de Direito, da Doris (CDDir). Por outro lado, 10 (40\%) bibliotecas não indicaram o nome do sistema utilizado conforme solicitado no formulário, escreveram apenas a palavra "Classificação", o que prejudicou a análise. 
Quadro 1 - Elementos utilizados no número de chamada das bibliotecas respondentes

\begin{tabular}{|c|c|c|c|c|c|c|c|c|}
\hline $\begin{array}{l}\text { Respon- } \\
\text { dente }\end{array}$ & Marca de coleção & $\begin{array}{c}\text { Sistema de } \\
\text { classificação }\end{array}$ & $\begin{array}{c}\text { Codificação de } \\
\text { autor }\end{array}$ & Marca da obra & Edição & Volume & Exemplar & Outros elementos \\
\hline 1 & & CDU & Cutter & & & & & \\
\hline 2 & \multicolumn{8}{|l|}{ Numeração fixa } \\
\hline 3 & & Classificação & Iniciais do autor & & & & & \\
\hline 4 & & Classificação & Cutter & & $\mathrm{x}$ & $x$ & & \\
\hline 5 & $x$ & CDD & Cutter & & $x$ & $x$ & & \\
\hline 6 & & CDD & Cutter-Sanborn & & $x$ & & & Ano \\
\hline 7 & & CDD & Cutter-Sanborn & & $\mathrm{X}$ ou ano & $x$ & $x$ & \\
\hline 8 & $\mathrm{X}$ & Classificação & Cutter & & $\mathrm{X}$ ou ano & & & \\
\hline 9 & \multicolumn{8}{|l|}{ Alfanumérico } \\
\hline 10 & $x$ & CDD & Cutter-Sanborn & & $\mathrm{X}$ ou ano & $\mathrm{x}$ & $\mathrm{X}$ & \\
\hline 11 & & CDU & & & & & & \\
\hline 12 & & CDD & Cutter-Sanborn & & $\mathrm{X}$ ou ano & $x$ & $x$ & \\
\hline 13 & & Classificação & Cutter & $\begin{array}{l}\text { Três primeiras letras } \\
\text { do título }\end{array}$ & & & & $\begin{array}{l}\text { Ano } \\
\text { Literatura - inicial do } \\
\text { país }\end{array}$ \\
\hline 14 & & Classificação & Cutter & & Ano & $\mathrm{X}$ & $\mathrm{x}$ & \\
\hline 15 & & Classificação & Autor & & $x$ & & & $\begin{array}{l}\text { № de registro } \\
\text { Sigla da biblioteca }\end{array}$ \\
\hline 16 & & $\mathrm{CDD}$ & Cutter & & & & & Ano \\
\hline 17 & & CDD & & & & & & \\
\hline 18 & & Classificação & Autor & & $\mathrm{X}$ ou ano & $\mathrm{x}$ & & \\
\hline 19 & & CDD & Cutter & & & & & \\
\hline 20 & & CDD+CDDir & Cutter-Sanborn & & & $x$ & $x$ & Ano \\
\hline 21 & & Classificação & Cutter & & & $\mathrm{X}$ & $\mathrm{x}$ & Ano \\
\hline 22 & & CDD & Cutter & $\mathrm{X}$ & Ano & $\mathrm{X}$ & $x$ & \\
\hline 23 & & CDD & Cutter-Sanborn & $x$ & Ano & & & \\
\hline 24 & & CDD & Cutter-Sanborn & & & & & \\
\hline 25 & & Classificação & Cutter & & Ano & $x$ & $\mathrm{X}$ & \\
\hline 26 & & Classificação & Cutter & & & & & \\
\hline
\end{tabular}

Fonte: elaboração própria 
Quanto à codificação de autor, 48\% (12 bibliotecas) utilizam a tabela de Cutter, 28\% (sete) a tabela de Cutter-Sanborn, 16\% (quatro) não especificaram o tipo de tabela utilizada, e $8 \%$ (duas) escreveram apenas a palavra autor. Essa pergunta foi aberta e o resultado foi semelhante ao da resposta à questão 4 que foi fechada.

Com relação aos elementos que integram o número de chamada é relevante ressaltar que apenas três (12\%) bibliotecas incluíram a marca de coleção como integrante do número de chamada. Já a marca da obra é utilizada por três (12\%) bibliotecas, das quais uma utiliza as três primeiras letras do título, forma que não se encontra relatada na literatura.

Quanto à marca de edição, 52\% incluem este elemento. Destes, $16 \%$ incluem a edição; $16 \%$ incluem o ano como indicativo de edição; $20 \%$ incluem a edição ou ano de publicação; e $48 \%$ dos respondentes não informaram incluir a marca de edição. Na coluna de outros elementos que integram o número de chamada $20 \%$ incluíram o ano, mas não especificaram se seria em substituição à marca de edição.

Quanto ao volume, $40 \%$ fazem uso da marca de volume, enquanto $60 \%$ não a utilizam. Em relação ao exemplar, apenas 32\% fazem uso da identificação do exemplar; os demais $68 \%$ não utilizam.

Apenas duas bibliotecas utilizam as três letras do sobrenome do autor, uma utiliza localização fixa, e outra utiliza o sistema de numeração fixa. Entre outras características citadas estão a utilização de letras que indicam o país de origem da obra, sigla da biblioteca e indicação de idioma do documento.

Quanto ao sistema de localização fixa, Maltby (1975) já argumentava que é um sistema antigo e primitivo, pois o livro tem um lugar permanente na estante. Tem como desvantagem o desagrupamento dos documentos por assunto, desfavorece a reunião de exemplares, volumes e edições, os diferentes livros de um mesmo autor e as traduções existentes, e inviabiliza o browsing, o manuseio direto nas estantes. Por outro lado, Pinheiro (2007) apresenta argumentação contrária.

Embora essa questão não tenha sido levantada neste estudo, o estudo de Kessler (2011) identificou que menos da metade das bibliotecas pesquisadas (46\%) possuem acesso aberto, apesar de na literatura encontrarem-se orientações quanto à vantagem do acesso aberto às estantes, especialmente no que se refere ao browsing, que oportuniza ao usuário entrar em contato com outras publicações cujos assuntos estão relacionados àquele que ele está buscando. A argumentação para a adoção da prática do acervo fechado em $54 \%$ das bibliotecas da Universidade Nacional do Prata deve-se:

a) as estantes estão desordenadas; b) o número de chamada não é um dado que os usuários sabem utilizar; c) os números auxiliares da CDU são complexos para o uso do usuário; d) não se adaptaram porque vem de um acesso fechado; e) preferem a 
comodidade de pedir ao bibliotecário e por isso não se esforçam para aprender a usar a biblioteca por si mesmos" (KESSLER, 2011, p. 56, tradução nossa)

A questão sete, fechada (sim e não) arguiu sobre a utilização da marca de coleção para compor o número de chamada. Dos respondentes, $70 \%$ fazem uso da marca de coleção, enquanto $30 \%$ não. Entretanto, na questão seis apenas três instituições afirmaram que a marca de coleção fazia parte do número de chamada utilizado na biblioteca. Observa-se uma diferença entre 12\% (instituições que utilizam a marca de coleção - questão seis) e 70\% (bibliotecas que detalharam os tipos de siglas utilizadas como marca de coleção - questão sete).

A figura 1 sintetiza as respostas à questão oito, na qual estão apresentadas as siglas utilizadas, seu significado e a quantidade de bibliotecas que as adota. Há tipos diferentes de materiais que compõem o acervo de algumas bibliotecas, que não constam no acervo de outras, como partituras e mapas, que constam apenas em duas bibliotecas. A marca de coleção foi indicada por apenas três instituições na questão seis. Já na questão oito praticamente todas as instituições possuem siglas para indicar diferentes tipos de materiais, o que aparentemente evidencia incoerência. Uma hipótese para tentar explicar esta incoerência observada pode ser atribuído à terminologia utilizada, marca de coleção, por outro lado, na literatura consultada, especializada na área, este termo é apresentado.

Foi observado que em duas bibliotecas há preocupação em manter a memória da instituição, pois possuem coleção com esta finalidade, conforme identificação da coleção por meio de U universidade e MEMO - coleção memória.

Merece menção o fato de Ranganathan (1967) dedicar, em seu livro, um capítulo para tratar da marca de coleção, refletir sobre os pontos positivos e negativos, defendendo seu uso para acesso ao documento. Ele defende a necessidade de individualizar as diferentes coleções de documentos a serem formadas com base nas peculiaridades do suporte ou característica física, raridade, ou exigência do serviço para facilitar o uso.

Na literatura não há consenso quanto às siglas a serem utilizadas. Lentino (1967), Mey (1995) e Ortega, Silva e Santos (2016) orientam que se deve padronizar, no âmbito da biblioteca, a utilização de uma letra, conjunto de letras, símbolos ou cor para indicar o tipo de suporte ou acervo a que o documento pertence. Cabe registrar que a forma como a instituição organiza sua coleção e as respectivas siglas utilizadas é uma decisão de cada uma, levando em consideração o tipo de material que possui e o atendimento aos usuários.

No estudo realizado por Kessler (2011, p. 57), foi identificado que $31 \%$ das bibliotecas pesquisadas "empregam cores para diferenciar o material quanto ao tema e ao setor ao qual o mesmo corresponde", que pode ser similar à marca de coleção. Ela argumenta que embora o uso de cores 
atreladas a assuntos tenha um aspecto interessante pois facilita o acesso ao público, há autores que "não recomendam o uso desse sistema tratando-se de bibliotecas universitárias". Com relação à área à qual se destina o material, que corresponde ao que se denomina marca de coleção, $23 \%$ das bibliotecas pesquisadas adotam este elemento para compor o número de chamada.

Figura 1 - Marcas de coleção utilizadas nas bibliotecas pesquisadas

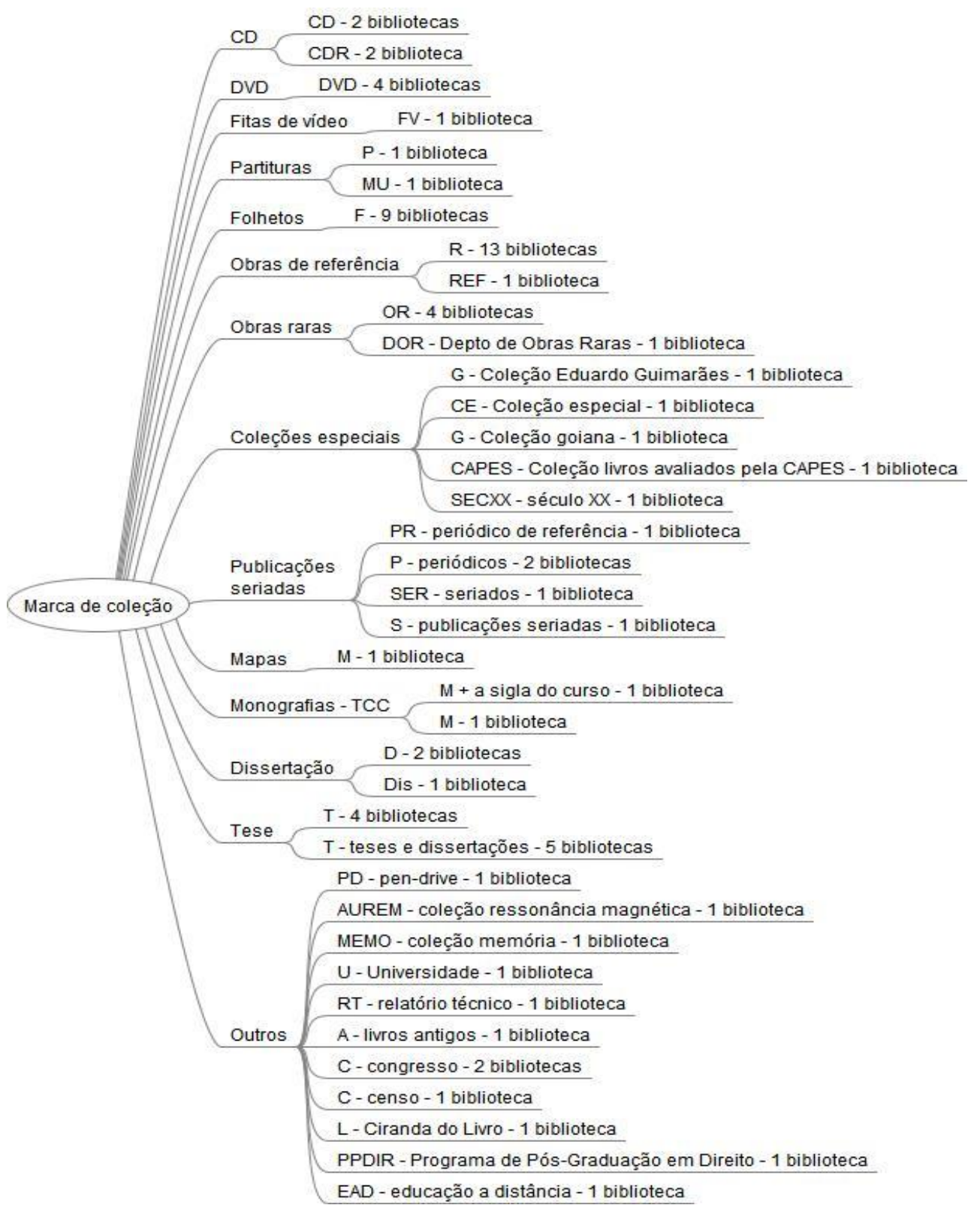

Fonte: elaboração própria. 
A questão de número nove tratou da utilização do indicativo de título ou marca da obra, $60 \%$ dos respondentes utilizam a marca da obra ou fazem uso do indicativo de título e $40 \%$ não. Entretanto, quando se comparam as respostas das questões seis e nove, observa-se incoerência nas respostas, pois apenas três bibliotecas (12\%) indicaram a marca da obra como integrante do número de chamada adotado na biblioteca. É interessante resgatar a literatura, pois Cutter $(1952,1962)$, Lehnus (1978) e Lentino (1967) sugerem que em grandes bibliotecas é necessário utilizar a marca da obra, pois pode haver diversos livros de um mesmo autor classificados em um mesmo assunto, fato que pode ocorrer nas bibliotecas universitárias. Entretanto, observou-se que $40 \%$ dos respondentes não a utilizam.

É necessário refletir quanto à terminologia adotada neste estudo utilizando o termo marca da obra, que significa a primeira letra do título. Na literatura estrangeira, Bertha Barden (1937) utilizava o termo title mark, ou na tradução literal marca de título. Posteriormente, Comaromi (1981) usa o termo como integrante do book number, representado por work mark (marca da obra). Na literatura brasileira não há consenso quanto à terminologia. Souza (2012) por exemplo, utiliza a denominação primeira letra do título; já na tradução do livro de Lehnus (1978) que foi realizada pela Profa. Hagar Espanha Gomes é adotado o termo marca da obra. No livro de Ortega, Silva e Souza (2016) também se constata o uso do termo marca da obra. Assim, observa-se que o termo marca da obra é adotado nas obras especializadas sobre número de chamada e notação de autor, tanto no Brasil quanto no exterior.

A adoção do indicativo de data para individualizar publicações como anais de congresso é bem popular, de acordo com Lehnus (1978) e, geralmente, utilizada em combinação com outros elementos individualizadores. As repostas à questão 10 evidenciam que $60 \%$ das bibliotecas fazem uso do indicativo de data para esse tipo de publicação, enquanto 40\% não. No estudo de Kessler (2011) apenas 15\% das bibliotecas pesquisadas fazem uso de indicativo de edição ou reimpressão.

Há uma prática alternativa de utilizar o ano em que a obra foi publicada no lugar da edição, que é defendida por autores como Comaromi (1981), Cutter (1904, 1952), Lehnus (1978), Lentino (1967) e Mann (1962). Entretanto, Barden (1937) não concorda com essa prática, pois desta forma está sendo introduzida uma variação na composição do book number.

Quanto ao indicativo de volume no número de chamada, as respostas à pergunta 11 evidenciaram que $92 \%$ o utilizam, e apenas $8 \%$ (duas) instituições não. Entretanto, as respostas a esta questão, quando comparadas com as da questão seis, apresentam incoerência, pois $44 \%$ indicaram que o volume integra o número de chamada e $66 \%$ não. No que se refere à forma de registrar esta informação, houve consenso entre os respondentes, que utilizam a letra $\mathbf{v}$ seguida de um ponto e o número do volume, conforme recomendado na literatura, v.1; v.2. (CUTTER, 1967; LEHNUS, 1978; 
LENTINO, 1967; MEY, 1995; ORTEGA; SILVA; SOUZA, 2016; PRADO, 1984). No estudo de Kessler (2011) foi observado que o indicativo de volume é utilizado por $26 \%$ das bibliotecas universitárias pesquisadas.

O uso do indicativo de exemplar, questão 13 , é adotado por $73 \%$ dos respondentes, enquanto $27 \%$ não o utilizam. Os resultados a esta questão, quando comparados com os da questão seis, também evidenciaram incoerência, pois apenas 32\% dos respondentes afirmaram que o indicativo de exemplar integrava o número de chamada. Entretanto, observa-se que há consenso quanto à forma de construí-lo: a abreviatura de exemplar, seguida de ponto e o número do exemplar, a partir do segundo exemplar, ex.2; ex.3, que vai ao encontro da literatura conforme orientam Cutter (1967), Lehnus (1978), Mey (1995) e Ortega, Silva e Santos (2016). No estudo de Kessler (2011), apenas 15\% das bibliotecas pesquisadas fazem uso do número de exemplar.

As questões 15 a 23 trataram das práticas adotadas na construção do número de chamada de obras relacionadas a outras obras. A questão 15, do tipo fechada, apresentou as alternativas: suplementos e índices, críticas e comentários e traduções, e solicitou a indicação de quais tipos de obras selecionadas eram tratadas pela biblioteca, podendo, o respondente, assinalar mais de uma opção. As obras mais tratadas foram as traduções, $85 \%$ (22 bibliotecas) dos respondentes afirmaram tratá-las, seguidas de suplementos e índices com 46\% (12 bibliotecas) e, por fim, as críticas e comentários com 35\% (9 bibliotecas) dos respondentes.

A questão 16, de tipo aberta, solicitava especificar a forma como o número de chamada para traduções era construído. Cabe ressaltar que 16 (64\%) bibliotecas responderam à questão e 36\% não o fizeram. As respostas foram reproduzidas no quadro 2 , pois foi constatado que não há similitude entre as práticas adotadas nas bibliotecas. Os elementos utilizados no número de chamada são diversificados e a forma de apresentação é também diferenciada.

Apenas uma instituição utiliza as orientações apresentadas na literatura por Cutter (1967), Lentino (1967) e Prado (1984) para tratar as traduções; as demais instituições usaram formas mais simplificadas, para atender a necessidades individuais, fruto de criação própria, sem respaldo verificado na literatura. Não foi identificado nenhuma convergência em termos de prática, o idioma para o qual o documento foi traduzido pode ser representado: por uma notação da tabela de língua da CDU; pela letra inicial do idioma, em maiúscula, em minúscula, traduzida para o português ou no idioma original, dentre várias outras formas observadas. Das 16 instituições respondentes cada uma utiliza uma forma diferente.

Quadro 2 - Construção do número de chamada para traduções nas bibliotecas pesquisadas 


\begin{tabular}{|c|c|}
\hline Respondente & Construção da Notação \\
\hline 1 & $\begin{array}{l}\text { O número de chamada - Classificação e notação de autor - permanece o mesmo da } \\
\text { obra no idioma original, e acrescenta-se o diferencial de idioma. Ex.: 869.0(81) } \\
\text { O48a }=20\end{array}$ \\
\hline 2 & $\begin{array}{l}\text { Cutter + primeira letra do título original, seguida do sinal de igual e a letra do } \\
\text { idioma traduzido Ex.: } C 455 \mathrm{~m}=\mathrm{p}\end{array}$ \\
\hline 3 & Pelo idioma da tradução \\
\hline 4 & Ex. ed.port., ed.eng., ed.fre., etc. \\
\hline 5 & $\begin{array}{l}\text { 1a letra do sobrenome do autor }+n \text { o do Cutter }+1 \text { a letra do título original + ponto }+ \\
\text { 1a letra da língua }+1 \text { a letra do sobrenome do tradutor. }\end{array}$ \\
\hline 6 & No Cutter a letra deverá corresponder ao título original \\
\hline 7 & Ed. port., Ed. ingl. etc. \\
\hline 8 & $\begin{array}{l}\text { Se houver exemplares em outros idiomas, adiciona-se ed.fra. (edição francesa), } \\
\text { ed.bras. (edição brasileira), etc. }\end{array}$ \\
\hline 9 & $\begin{array}{l}\text { Coloca-se a primeira letra do título original e a primeira letra da língua em que o } \\
\text { livro está escrito. }\end{array}$ \\
\hline 10 & $\begin{array}{l}\text { Coloca-se uma nota geral informando que é uma tradução de: e coloca-se o título } \\
\text { original da obra }\end{array}$ \\
\hline 11 & Classificação específica, primeira letra do autor e primeira letra do título \\
\hline 12 & $\begin{array}{l}\text { É colocada a inicial do idioma ao lado do código de Autor } \\
\text { (Sobrenome/Cutter/Título): 869.0(81) E42d-P. "P" seria para indicar tradução para } \\
\text { português. }\end{array}$ \\
\hline 13 & $\begin{array}{l}C D D \text {, Cutter e marca da obra (formada pela primeira palavra do título original } \\
\text { seguida da letra } \mathrm{P}=\text { português, idioma da tradução). }\end{array}$ \\
\hline 14 & $\begin{array}{l}\text { Se a entrada principal for pelo título: utiliza-se o Cutter do título na língua original } \\
\text { seguido da letra do idioma em que a obra se encontra traduzida. ex. título do livro: } \\
\text { Mentiras que parecem verdades. tradução de: I Pampinibugiardi construção do no } \\
\text { de chamada: assunto } 371.32 \text { Cutter P186p } 1985 \text { P186 de Pampini p - tradução } \\
\text { português }\end{array}$ \\
\hline 15 & $\begin{array}{l}\text { Nota na catalogação e no Cutter colocar a primeira letra referente à língua do } \\
\text { documento }\end{array}$ \\
\hline 16 & Pelo sobrenome do autor original da obra \\
\hline
\end{tabular}

Fonte: elaboração própria.

A questão 17 solicitou informações quanto à construção do número de chamada para obras que são índices e suplementos de outras obras. Apenas 6 (24\%) instituições responderam a esta questão. Esse baixo nível de resposta pode dar margem a algumas hipóteses: que a biblioteca não faz diferença no número de chamada; que trata como um documento novo e não o aproxima da obra com a qual se relaciona. Quanto à forma de indicar esses materiais, as respostas apresentadas seguiram um padrão, por meio da utilização de siglas: supl. (suplemento) e ind. (índices), que seguem as orientações apresentadas na literatura por Barden (1937), Cutter (1967) e Lehnus (1978).

A questão 18 questionou sobre as práticas adotadas para construção do número de chamada de obras que se constituem em críticas e comentários a outras obras, como obras relacionadas. 
Observou-se um percentual muito baixo de resposta, apenas quatro (16\%) bibliotecas responderam à questão. Não foram observadas semelhanças nas respostas, cada uma possui uma forma específica de tratar esse tipo de material, por esse motivo foram reproduzidas no quadro 3. Apenas uma biblioteca utiliza a letra Y conforme orientação de Cutter (1967) para indicar comentários e críticas a outras obras.

Quadro 3 - Construção da notação para críticas e comentários nas bibliotecas pesquisadas

\begin{tabular}{|c|l|}
\hline Respondentes & \multicolumn{1}{c|}{ Construção da Notação } \\
\hline 1 & $\begin{array}{l}\text { O número de chamada é construído com a Classificação pertinente, notação do } \\
\text { autor criticado seguido de .Y e letra do crítico. Ex.: 869.0(81) O48.Yc }\end{array}$ \\
\hline 2 & 1a letra do sobrenome do comentado + no do Cutter + 1ạ letra do comentador. \\
\hline 3 & Classificação específica, primeira letra do autor e primeira letra do título \\
\hline 4 & $\begin{array}{l}\text { Utilizamos a tabela auxiliar de forma da CDU e/ou as subdivisões auxiliares da Classe } \\
\text { (Literatura, por exemplo). Não há diferença no uso do Cutter, que permanece o do } \\
\text { autor. }\end{array}$ \\
\hline
\end{tabular}

Fonte: elaboração própria.

As questões 19 e 20 indagaram sobre as práticas adotadas na construção da notação de biografias e autobiografias, 13 (52\%) bibliotecas responderam à questão, cujas respostas relativas às biografias foram reproduzidas no quadro 4. Dos respondentes à questão, duas bibliotecas incluem as biografias na coleção de obras de referência. Quanto a essas respostas pode-se questionar se biografia consiste em um tipo de obra de referência. Quatro bibliotecas utilizam as orientações da CDD para construção do número de classificação, das quais uma adota o número de Cutter para o autor da obra, as demais não especificaram como a notação de autor é construída. Três respondentes informaram a construção da notação de autor da forma como está orientado na literatura (CUTTER, 1969), ou seja, a primeira letra do sobrenome do biografado, com seu respectivo número extraído da tabela de Cutter, seguido da primeira letra do sobrenome do biógrafo.

Cabe ressaltar que, de acordo com a literatura consultada, o tratamento das autobiografias e as biografias para fins de organização nas estantes varia em consequência do sistema de classificação utilizado. Porém, a regra geral é que a notação de autor seja construída com base no sobrenome do biografado, e a sua autobiografia deve preceder, na organização das estantes, a sua biografia.

Quadro 4 - Construção da notação para biografias

\begin{tabular}{l|ll} 
Respondente $\quad$ Construção da Notação & C
\end{tabular}




\begin{tabular}{|c|l|}
\hline 1 & $\begin{array}{l}\text { Utilizamos a Classificação 929(biografias), o Cutter do biografado com a letra do } \\
\text { autor da obra após a notação. Ex.: 929 M772c }\end{array}$ \\
\hline 2 & O Cutter tem como entrada o biografado. \\
\hline 3 & A catalogação é normal, ordinária, e a notação é normal. \\
\hline 4 & Utilizando as ferramentas da CDD \\
\hline 5 & 1a letra do sobrenome do biografado + no do Cutter + 1a letra do biógrafo. \\
\hline 6 & $\begin{array}{l}\text { Classificação, Cutter do biografado e letra inicial minúscula do autor da } \\
\text { biografia. }\end{array}$ \\
\hline 7 & Na classe 900 da CDD mais Cutter-Sanborn do autor \\
\hline 8 & São colocadas como referência \\
\hline 9 & $\begin{array}{l}\text { Para biografias individuais utilizamos o Cutter do biografado, seguido da inicial } \\
\text { do autor da biografia. }\end{array}$ \\
\hline 10 & A notação é constituída com base na CDD. \\
\hline 11 & Notação corresponde ao sobrenome do autor da biografia. \\
\hline 12 & Utiliza-se a notação base 920 da CDD mais a notação 000-999 \\
\hline 13 & Colocamos na coleção de referência com R \\
\hline
\end{tabular}

Fonte: elaboração própria.

O quadro 5 reproduz as respostas relativas aos procedimentos adotados para as autobiografias, que corresponde a 44\%, ou seja, 11 respondentes. Observou-se que cada instituição adota uma prática diferente. Como já citado acima, as autobiografias devem preceder as biografias na arrumação das estantes, para isso deve ter um número de chamada que favoreça essa ordenação.

Quadro 5 - Construção da notação para autobiografia

\begin{tabular}{|c|l|}
\hline Respondente & \multicolumn{1}{c|}{ Construção da Notação } \\
\hline 1 & $\begin{array}{l}\text { Mesma construção utilizada em biografias, porém ao invés da letra de autor após o } \\
\text { Cutter é empregada a letra "a", Ex.: 929 M772a }\end{array}$ \\
\hline 2 & Autor/Título \\
\hline 3 & 1a letra do sobrenome do biografado + no do Cutter + 1a letra do biógrafo. \\
\hline 4 & Na classe 900 da CDD mais Cutter-Sanborn do autor \\
\hline 5 & Cutter do autor (biografado) \\
\hline 6 & A mesma maneira dos demais \\
\hline 7 & É utilizado o no de classificação mais o Cutter do autor/biografado e inicial do título. \\
\hline 8 & Seria como dos demais livros \\
\hline 9 & A notação é constituída com base na CDD. \\
\hline 10 & Notação corresponde ao sobrenome do autobiografado. \\
\hline 11 & A mesma de Biografias \\
\hline
\end{tabular}

Fonte: elaboração própria. 
A questão 21 tratou das genealogias: $77 \%$ dos respondentes constroem a notação da mesma maneira adotada para os documentos do acervo geral, sem nenhuma distinção. Para $23 \%$ dos respondentes esse tipo de documento não faz parte do acervo.

A questão 22 questionou sobre a construção da notação para obras como catálogos e bibliografias: $57,7 \%$ utilizam as mesmas regras do acervo geral, enquanto $42,3 \%$ não possuem esse tipo de documento em seu acervo.

O último tipo de obra que a pesquisa analisou foram os periódicos. No quadro 6 foram reproduzidas as respostas.

A variação das respostas quanto à construção da notação de periódicos é a mais dinâmica e flexível nas bibliotecas pesquisadas. Dentre elas é possível identificar a utilização da organização em ordem alfabética do título, inserindo-os na coleção de referência e até mesmo não utilizando número de chamada para esses documentos. Porém, os que utilizam, afirmam que a notação é composta por identificador de coleção, classificação, letra inicial do título e o número da posição na estante ou apenas o identificador da coleção, a classificação e a letra inicial do título do periódico.

Quadro 6 - Construção da notação para periódicos nas bibliotecas pesquisadas

\begin{tabular}{|c|l|}
\hline Respondentes & \multicolumn{1}{|c|}{ Construção da Notação } \\
\hline 1 & Alfa cronológico \\
\hline 2 & Autor/Título \\
\hline 3 & $\begin{array}{l}\text { Não tem número de chamada. Ficam em uma parte do armazém distribuídos por } \\
\text { ordem alfabética de título. }\end{array}$ \\
\hline 4 & Não utilizamos. São arquivados em ordem alfabética de título. \\
\hline 5 & Os periódicos não recebem número de chamada. \\
\hline 6 & $\begin{array}{l}\text { Identificador de coleção, classificação, letra inicial do título, número de posição } \\
\text { na estante }\end{array}$ \\
\hline 7 & Ano, volume e número do fascículo. \\
\hline 8 & $\begin{array}{l}\text { O periódico é classificado somente no Sistema. Na estante é organizado em } \\
\text { ordem alfabética. }\end{array}$ \\
\hline 9 & $\begin{array}{l}\text { P (de periódicos) e numeração referente ao título do periódico que foi atribuído } \\
\text { por nossa equipe. }\end{array}$ \\
\hline 10 & $\begin{array}{l}\text { É utilizada a sigla de coleção "P", mais o número de classificação e a sigla A/Z, } \\
\text { uma vez que o armazenamento é por assunto e dentro deste por título: P 5/6 } \\
\text { A/Z }\end{array}$ \\
\hline 11 & $\begin{array}{l}\text { Não utilizamos número de chamada para periódicos. } \\
\text { O número de chamada é construído pela divisão por área do título do periódico } \\
\text { (GF = Geografia, GR = Assuntos Gerais, GL = Geologia, IQ = Química, ME = } \\
\text { Meteorologia, RF = Referência), seguido do número de Cutter do título do } \\
\text { periódico. }\end{array}$ \\
\hline 12 & $\begin{array}{l}\text { Como a biblioteca possui uma grande quantidade de títulos de periódicos } \\
\text { (2.009), eles são guardados em ordem numérica. ex. P/0001. A notação da } \\
\text { etiqueta fica: P/O001 v.1(1) }\end{array}$ \\
\hline 13 & \\
\hline
\end{tabular}


Fonte: elaboração própria.

Com o objetivo de analisar quantas bibliotecas possuem políticas de composição do número de chamada, foi elaborada a questão 24 que questionou quanto a existência de manual ou orientações escritas/formalizadas para a construção do número de chamada. Observou-se que 46\% dos respondentes possuem algum tipo de manual, enquanto $54 \%$ não.

Kessler (2011, p. 60) ressalta que, embora um manual de procedimentos que indique a maneira correta e os critérios a serem adotados para a prática da organização da informação no âmbito da biblioteca, especialmente no que se refere ao número de chamada não seja suficiente para resolver o problema de acesso nas bibliotecas universitárias da rede da Universidade Nacional do Prata, "é um ponto de partida para evitar a aplicação de critérios errôneos na atividade cotidiana".

\section{Discussão e conclusão}

O número de chamada tem, de forma simplificada, a função de localizar o documento na estante, ele tem uma base teórica subjacente, cada um dos seus elementos tem uma função específica. A marca da obra agrupa os documentos por uma característica física ou suporte; o número de classificação ou notação de classificação tem por objetivo reunir os documentos que tratam de mesmo assunto - reunir os semelhantes a partir de uma característica interna; já a notação de autor, marca da obra, edição, volume e exemplar têm como objetivo individualizar a obra dentro da classe. As obras relacionadas, por sua vez, são aquelas que se referem a outras obras, por isso devem estar próximas, nas estantes, das obras com as quais se relacionam. Por isso, no número de chamada serão incluídos outros elementos que evidenciam essa relação.

A pesquisa surgiu da constatação da carência de literatura e pesquisa na área relativa ao número de chamada, que tem como finalidade ordenar os recursos informacionais que integram o acervo de forma a possibilitar a localização de forma rápida dos itens catalogados. Teve como objetivo analisar as práticas adotadas pelas bibliotecas brasileiras para construção do número de chamada. Para isso foram identificados os elementos utilizados na construção do número de chamada, bem como a forma como as características do documento são representadas; foram analisadas as similitudes nas escolhas desses elementos e nas práticas, bem como a aderência com a literatura da área. O estudo usou as bibliotecas das universidades federais, como amostra, por possuírem grandes e diversificados acervos. Para isso contatou as 68 bibliotecas universitárias federais e obteve respostas de 26 (38,24\% do total); utilizou como instrumento de coleta de dados o questionário, composto por questões abertas e fechadas, encaminhado via e-mail, utilizando o Google forms. 
As bibliotecas pesquisadas possuem grandes acervos, cujos recursos informacionais precisam ser reunidos aos seus semelhantes por meio da marca de classificação, e individualizados nesta por meio dos demais elementos que compõem o número de chamada.

Na pesquisa observou-se que diversos elementos não são considerados na construção do número de chamada, especialmente aqueles que individualizam o documento, bem como para o tratamento das obras relacionadas. Conclusão semelhante foi apresentada no estudo de Kessler (2011), ao que ela atribuiu a falta de capacitação e experiência na catalogação e classificação. Ela destaca que "algumas bibliotecas preferem construir seus sistemas de notação próprios quando tem a disposição outros testados e eficientes" (KESSLER, 2011, p. 59, tradução nossa).

Outro ponto de grande relevância refere-se ao uso da terminologia. Embora tenha sido observada na literatura uma quantidade reduzida de documentos sobre o assunto, que especificam uma terminologia especializada na área, tais como: marca da obra, marca de coleção etc. observa-se que esses termos ainda não são de domínio dos profissionais bibliotecários.

A pesquisa evidenciou que há algumas semelhanças, entre as bibliotecas pesquisadas, quanto aos elementos que integram o número de chamada, bem como quanto aos instrumentos e práticas utilizados para sua construção. Embora tenham sido observadas discrepâncias entre respostas às questões abertas e fechadas, pode-se inferir que o número de chamada, utilizado nas universidades federais brasileiras, encontra certa aderência com a literatura no que se refere aos elementos básicos que o integram.

Analisando-se as respostas foram constatadas inconsistências entre as questões, sobre um mesmo assunto, apresentadas na forma aberta ou fechada. Exemplificando: quanto aos elementos que integram o número de chamada, por meio de questão aberta, foi constatado que diversos elementos que são identificados na literatura como integrantes do número de chamada não foram listados pelos respondentes. Entretanto, ao serem solicitadas informações diretamente sobre um desses elementos, incoerências foram observadas nas respostas quando comparadas à resposta da questão seis. Um exemplo: apenas 3 bibliotecas (12\%) responderam que a marca de coleção integra o número de chamada (questão seis); entretanto, quando solicitada a indicação dos tipos de marca de coleção utilizadas (questão sete), 70\% responderam que usam este elemento. Outro exemplo referese à marca da obra ou indicativo de título, em que $88 \%$ dos respondentes não incluíram a marca da obra na questão seis, porém na questão nove, que tratou especificamente sobre o tema, $60 \%$ dos respondentes afirmaram que utilizam a marca da obra. Também quanto ao indicativo de volume, exemplar, observou-se fenômeno semelhante. No quadro 7 estão sintetizadas as similitudes observadas na construção do número de chamada. 
No estudo realizado por Kessler (2011), também foi observada falta de padronização no uso dos elementos para a construção da signatura librística ou book number. Os elementos listados por Kessler têm formas diferenciadas de apresentação que não foram identificadas na literatura consultada neste estudo.

Quadro 7 - Similitudes observadas nos elementos essenciais do número de chamada

\begin{tabular}{|c|c|c|}
\hline Uso de & Percentual & Comentários \\
\hline Número de chamada & $96 \%$ & $\begin{array}{l}\text { Praticamente todas as bibliotecas utilizam número de } \\
\text { chamada como localizador. }\end{array}$ \\
\hline Sistema de classificação & $92 \%$ & $\begin{array}{l}\text { Praticamente todas as bibliotecas utilizam um sistema } \\
\text { de classificação. }\end{array}$ \\
\hline Marca de coleção & $70 \%$ & $\begin{array}{l}\text { Listaram as siglas que são utilizadas em suas bibliotecas, } \\
\text { por este motivo pode-se inferir que } 70 \% \text { a utilizam. }\end{array}$ \\
\hline Número de classificação & $92 \%$ & $\begin{array}{l}\text { O número de classificação integra o número de chamada } \\
\text { de } 92 \% \text { das bibliotecas pesquisadas. }\end{array}$ \\
\hline Marca de autor & $96 \%$ & $\begin{array}{l}\text { A marca de autor integra o número de chamada de } 96 \% \\
\text { das bibliotecas pesquisadas. } 76 \% \text { das bibliotecas } \\
\text { pesquisadas utilizam tabelas de Cutter. }\end{array}$ \\
\hline Marca da obra & $60 \%$ & $\begin{array}{l}\text { Pelo quantitativo considerado baixo em relação aos } \\
\text { acima mencionados, pode-se inferir que há problemas } \\
\text { de entendimento dos termos utilizados neste estudo. }\end{array}$ \\
\hline Marca de edição & $52 \%$ & $\begin{array}{l}16 \% \text { adotam o número de edição; } 16 \% \text { ano como } \\
\text { indicativo de edição; } 20 \% \text { edição ou ano. Desta forma, } \\
\text { não foi detectada padronização nas práticas. }\end{array}$ \\
\hline Marca de volume & $92 \%$ & Padrão na forma de representar. v. 1; v. 2 \\
\hline Marca de exemplar & $73 \%$ & Padrão na forma de representar ex.2; ex.3 \\
\hline
\end{tabular}

Fonte: elaboração própria

Em relação à construção do número de chamada de obras relacionadas a outras obras existentes no acervo, $85 \%$ dos respondentes tratam as traduções, $46 \%$ tratam os suplementos e índices e 35\% as críticas e comentários. Nesse caso, também, se observou a mesma incongruência comentada acima. Quanto às traduções somente $16(64 \%)$ respondentes informaram como constroem a notação para traduções e, apenas uma utiliza as orientações apresentadas na literatura, as demais utilizam formas e elementos próprios, não sendo observadas práticas comuns. Quanto aos índices e suplementos, 6 (24\%) instituições responderam a esta questão e seguiram um padrão, conforme sugere a literatura. Quanto às críticas e comentários, 4 (16\%) instituições responderam à questão e somente uma segue as orientações apresentadas por Cutter (1967). Informações consolidadas compõem o quadro 8. 
Quadro 8-Elementos utilizados para representar obras relacionadas

\begin{tabular}{|l|c|l|}
\hline \multicolumn{1}{|c|}{ Tipo de obra } & Percentual & \multicolumn{1}{c|}{ Comentários } \\
\hline Traduções & $85 \%$ & $\begin{array}{l}\text { Apenas uma instituição adota as orientações apresentadas } \\
\text { por Cutter (1967). As demais apresentaram formas } \\
\text { totalmente diferentes. Não foram identificadas similitudes } \\
\text { nas práticas. }\end{array}$ \\
\hline $\begin{array}{l}\text { Suplementos e } \\
\text { índices }\end{array}$ & $42 \%$ & $\begin{array}{l}\text { Apenas 24\% (6 instituições) responderam quanto à forma } \\
\text { utilizada. Observada convergência quanto a forma utilizada: } \\
\text { supl. (suplemento); ind. (índices). Ambas as formas } \\
\text { compatível com a literatura. }\end{array}$ \\
\hline $\begin{array}{l}\text { Críticas e } \\
\text { comentários }\end{array}$ & $35 \%$ & $\begin{array}{l}\text { 16\% (quatro bibliotecas) informaram a prática adotada. } \\
\text { Apenas uma utiliza as orientações de Cutter (1967). }\end{array}$ \\
\hline
\end{tabular}

Fonte: elaboração própria

Quanto ao número de chamada para biografias e autobiografias $52 \%$ responderam que trata esse tipo de material. Observou-se que as bibliotecas não seguem os procedimentos orientados na literatura, buscando resolver o problema por meio do uso das alternativas oferecidas pelo sistema de Classificação Decimal de Dewey (CDD) e outras formas, o que não pode ser considerado incorreto, pois os sistemas de classificação oferecem alternativas para colocar as autobiografias e as biografias próximas nas estantes. Quanto às genealogias e catálogos, 77\% dos respondentes informaram que tratam esses documentos como qualquer obra que é incorporada ao acervo geral e $23 \%$ não possuem esse tipo de material. Informações quanto a semelhanças e diferenças foram consolidadas no quadro 9.

Quadro 9 - Elementos utilizados para representar biografias, autobiografias e genealogias

\begin{tabular}{|l|c|l|}
\hline \multicolumn{1}{|c|}{ Tipo de obra } & Percentual & \multicolumn{1}{|c|}{ Comentários } \\
\hline Biografias & $52 \%$ & $\begin{array}{l}\text { Formas diferenciadas de tratar biografias. Similitudes quanto } \\
\text { ao uso do sobrenome do biografado (5 instituições, } \\
\text { corresponde a 20\%). }\end{array}$ \\
\hline Autobiografia & $44 \%$ & $\begin{array}{l}\text { Práticas diferenciadas para construção do número de } \\
\text { chamada. Não foram observadas similitudes quanto as } \\
\text { práticas. }\end{array}$ \\
\hline Genealogias & $77 \%$ & Adotam a mesma forma utilizada para o acervo geral \\
\hline
\end{tabular}

Fonte: elaboração própria.

Quanto aos periódicos as formas observadas foram diversificadas, porém há tendência ao uso da ordem alfabética dos títulos.

Observou-se, também, que $46 \%$ possuem algum tipo de manual orientando e padronizando a construção do número de chamada no âmbito da biblioteca e $54 \%$ não possuem. 
A partir deste estudo emergiram questões que merecem reflexão ou estudos mais aprofundados, bem como publicações na área, de forma a oferecer alternativas que favoreçam a construção do número de chamada: como as obras relacionadas são agrupadas junto às obras originais, se não é por meio do número de chamada? Quais são as diferentes alternativas utilizadas para tratar e representar as traduções e mantê-las próximo da obra original? Quais são os sistemas de classificação utilizados, o nível de classificação, uso de tabelas auxiliares? Quais motivos levam uma biblioteca universitária a adotar localização fixa e acesso fechado às estantes? Qual conteúdo os cursos de graduação em Biblioteconomia estão ministrando sobre número de chamada?

Para outras pesquisas a serem realizadas sobre o tema, sugere-se a definição dos termos utilizados pois pode-se inferir que não há o mesmo entendimento quanto à terminologia. Outra recomendação que emerge deste estudo refere-se à metodologia que, à exemplo de Kessler (2011) pode ser realizada por meio de consulta aos catálogos das bibliotecas, identificando a forma como os números de chamada foram construídos.

Constata-se que a área ainda merece a atenção de pesquisadores da Biblioteconomia, no sentido de avaliar o processo de ensino aprendizagem das disciplinas que tratam do tema, da literatura disponível no Brasil sobre o tema, dentre algumas sugestões de pesquisas futuras, pois o livro, na concepção gutenberguiana, ainda vai existir por algum tempo.

\section{Referências}

BARDEN, Bertha R. Book number: a manual for students with a basic code of rules. Chicago: American Library Association, $1937 . \quad 31 \mathrm{p} .10$ Disponível <http://babel.hathitrust.org/cgi/pt?id=mdp.39015033787162;view=1up;seq=7 >. Acesso em: 2 mar. 2017.

CARIBÉ, Rita de Cássia do Vale. Notação de autor: sua história. Informação e Sociedade: estudo,. João Pessoa, v. 26, n. 2, p. 121-135, maio/ago. 2016. Disponível em: <http://www.ies.ufpb.br/ojs2/index.php/ies/article/view/28650>. Acesso em: 8 fev. 2017.

CARIBÉ, Rita de Cássia do Vale. Ordenamento de documentos em bibliotecas: tipologia. Informação e Sociedade: estudo,. João Pessoa, v. 29, n. 2, p. 125-144, abr./jun. 2019.

COMAROMI, John Phillip. Book numbers: a historical study and practical guide to their use. Littleton: Libraries Unlimited, 1981. 145p.

CUTTER, Charles Ammi. Another plan for numbering books. Library Journal, New York, v. 3, n. 7, p. 248-251, Sept. 1878.

CUTTER, Charles Ammi. Cutter-Sanborn: three-figure author table. Englewood: Libraries Unlimited, 1969. 36p. 
CUTTER, Charles Ammi. Explanação das marcas de autor Cutter-Sanborn: tabelas com três algarismos. Rio de Janeiro: Departamento Administrativo do Serviço Público, Departamento de Imprensa Nacional, 1952.

CUTTER, Charles Ammi. Explanação das marcas de autor Cutter-Sanborn: tabelas com três algarismos. 2. ed. Rio de Janeiro: Departamento Administrativo do Serviço Público, Departamento de Imprensa Nacional, 1962.

GIL, Antônio Carlos. Métodos e técnicas de pesquisa social. 6. ed. São Paulo: Atlas, 2008. 220 p.

JAST, Louis. Stanley. A new book number. The Library World, London, v. 3, n. 5, p. 120-123, 1901.

JAST, Louis. Stanley. A new book number. The Library World, London, v. 3, n. 6, p. 150-152, 1901.

KESSLER, María Inés. El orden de los libros en el estante: un estudio sobre la signatura topográfica en las bibliotecas universitarias de la Universidad Nacional de La Plata. Revista Interamericana de Bibliotecología, Medellin, v. 34, n. 1, p. 49-61, 2011.

LEHNUS, Donald J. Notação de autor: manual para bibliotecas. Rio de Janeiro: BNG/Brasilart, 1978. $83 p$.

LENTINO, Noêmia. Classificação decimal universal (CDU): seu desenvolvimento, sua atualização. São Paulo: Folco Masucci, 1967. 127p.

LENTINO, Noêmia. Guia teórico, prático e comparado dos sistemas de classificação bibliográfica. São Paulo: Polígono, 1971. 407p.

MALTBY, Arthur. Sayer's Manual of classification for librarians. London: André Deutsch, 1975. 336p.

MEY, Eliane Serrão Alves. Catalogação e descrição bibliográfica: contribuições a uma teoria. Brasília: ABDF, 1987. 201p.

MEY, Eliane Serrão Alves. Introdução à catalogação. Brasília: Briquet de Lemos, 1995. 123p.

ORTEGA, Cristina Dotta; SILVA, Camila Mariana Aparecida da Silva; SANTOS, Marcelo Nair. Ordenação de documentos na atividade bibliográfica. Brasília: Briquet de Lemos, 2016. 146p.

OSBORN, Jeanne. Dewey Decimal Classification, $19^{\text {th }}$ edition: a study manual. Littleton: Libraries, 1982, $366 p$.

PINHEIRO, Ana Virgínia. A ordem dos livros na biblioteca. Rio de Janeiro: Interciência, 2007. 66p.

PRADO, Heloisa de Almeida. Organização e administração de bibliotecas. 2.ed. Rio de Janeiro: Livros Técnicos e Científicos, 1979. 221p.

RANGANATHAN, Shiyali Ramamrita. Prolegomena to Library Classification. New York: Asia Publishing House, 1967. Disponível em: <http://arizona.openrepository.com/arizona/handle/10150/106370>. Acesso em: 02 jul. 2011. 
RICHARDSON, Roberto Jarry et al. Pesquisa social: métodos e técnicas. 3. ed. São Paulo: Atlas, 1999. $334 p$.

SLAVIC, Aida. Call numbers, book numbers \& collection arrangements in European Library Traditions. In.: SINGH, Jagtar; MALHAN, Indervir; KAUR, Trishanjit (ed). Library \& information Science in digital age. Portland: International Specialized Book Service, 2009. 2v. Cap. 25, p. 257-285.

TAYLOR, Arlene G.; JOUDREY, Daniel N. The organization of information. 3.ed. London: Libraries, 2009. $512 p$. 


\section{Número de Chamada}

O objetivo desta pesquisa é conhecer as práticas adotadas na construção do número de chamada pelas bibliotecas das universidades federais brasileiras. As respostas serão utilizadas

exclusivamente para fins acadêmicos. Para responder às perguntas serão necessários entre 5 a 8

minutos. Desde já agradecemos a sua colaboração.

* Required

1. Identifique a sua biblioteca e a universidade à qual pertence *

Your answer

2. A biblioteca utiliza o número de chamada para localização dos documentos nas estantes? *

Sim

Não

3. A biblioteca utiliza um sistema para codificar autor? *

Sim

Não

4. Em caso afirmativo, qual o sistema utilizado?

Cutter

Cutter-Sanborn

( Tabela PHA 
Other:

5. Qual o critério utilizado para casos especiais, como editora/ano/data?

Your answer

6. Quais elementos utiliza em seu número de chamada?

Your answer

7. Utiliza siglas para marca de coleção? *

$\bigcirc \operatorname{sim}$

Não

8. Em caso de afırmativo, quais siglas são utilizadas e o que elas significam?

Your answer

9. Utiliza indicativo de título ou marca da obra? *

$\bigcirc \operatorname{sim}$

$\bigcirc$ Não

10. Utiliza o indicativo de data, em publicações como anais de congresso? *

$\bigcirc \operatorname{sim}$

! $\bigcirc$ Não 
11. Utiliza o indicativo de volume? *

$\bigcirc \operatorname{sim}$

$\bigcirc$ Não

12. Em caso afirmativo, especifique:

Your answer

13. Utiliza o indicativo de exemplar? *

$\bigcirc \operatorname{sim}$

$\bigcirc$ Não

14. Em caso afirmativo, especifique:

Your answer

15. Quais tipos de obras relacionadas são tratadas pela biblioteca?

Suplementos e indíces

Críticas e Comentários

Traduções

16. Qual o tratamento dado a traduções, como a notação é construída?

Your answer 
17. Qual o tratamento dado a suplementos e índices, como a notação é construída?

Your answer

18. Qual o tratamento dado a críticas e comentários, como a notação é construída?

Your answer

19. Como é construída a notação para Biografias?

Your answer

20. Como é construída a notação para autobiografias?

Your answer

21. Como é construída a notação para genealogias?

Your answer

22. Como é construída a notação para catálogos e bibliografias?

Your answer

23. Como é construído o número de chamada de periódicos?

Your answer

24. A biblioteca possui algum manual ou orientações descritas em um documento para orientar a construção do número de chamada? *

! $\bigcirc \mathrm{Sim}$

$-$ 
$\cup$ Não

25. Em caso afirmativo poderia encaminhar cópia desse documento?

Enviar cópia do documento para o email: ana.is.izabel@hotmail.com 